\title{
Price indices for artists - A proposal
}

\author{
Guido Candela \\ Paolo Figini \\ Antonello E. Scorcu \\ Department of Economics \\ University of Bologna*
}

This version: February 2003

\begin{abstract}
This paper proposes a price index for artists based on the ratio between the average market price and the average estimated price of the paintings sold by an artist each year, adjusted for market dynamics. We apply this methodology to a group of selected artists and schools drawing from a database including auction prices and estimated prices of paintings presented in auctions world wide between 1990 and 2001. A comparison with quality unadjusted and hedonic indices is also proposed.
\end{abstract}

J EL Classification: C10, Z11

Keywords: price indices, auctions, paintings, hedonic price

\footnotetext{
* Corresponding author: Antonello E. Scorcu. Dipartimento di Scienze Economiche, Strada Maggiore 45, Università di Bologna, I-40126 Bologna. Tel. +39 051 2092611; fax +39 051 2092664; e-mail: scorcu@spbo.unibo.it. The collaboration of Gabrius S.p.A., Milan, Italy is gratefully acknowledged. The authors thank Elena Bellini and Roberto Cenci for research assistance and V. Ginsburgh, W. Goetzmann, D. Liberanome and participants to the ACEI Conference, Rotterdam, June 2002, for extensive discussion on the indices, the methodology and the data used. The usual disclaimers apply.
} 


\section{I ntroduction}

The understanding of the mechanisms at work in the market for paintings needs a reliable price measurement which is, however, problematic because of the heterogeneity. Four methodologies have been developed in order to overcome this difficulty: (i) price indices that evaluate a portfolio of paintings selected through experts' personal judgements (like Reitlinger 1963 and 1970); (ii) indices based on the repeat sales methodology (like Anderson 1974, Goetzmann 1993, and Pesando 1993); (iii) indices based on hedonic regressions (like Frey and Pommerehne 1989, Buelens and Ginsburgh 1993, and Chanel 1995); (iv) indices based on the evaluation of a representative painting defined accordingly to given criteria (like Stein 1977, and Candela and Scorcu 1997).

Even if most of these indices insist upon the heterogeneity and the idiosyncrasy of specific segments, perhaps because of the limited number of artists for which an adequate information is available, their focus has often been on the evaluation of market for paintings as a whole. However, collectors usually specialise in few authors or schools, so that their typical art portfolios are characterised by a low degree of diversification and the evaluation of the rate of return of a typical investment might differ substantially from the market return. By improving the knowledge of price dynamics in different segments of the market, alternative investment opportunities characterised by different risk and average rates of return to investment can be better identified. More efficient diversification techniques might also be detected, by allowing comparisons within the art market and between art and other forms of investment. Moreover, the existing indices for authors or for specific segments of the art market use methodologies that can not be easily generalised ${ }^{1}$.

In this paper we try to develop indices for the cases in which for an artist a (relatively) low number of observations is available ${ }^{2}$. A related goal of the paper is to shed some light on the aggregation of artists into indices for schools and artistic movements.

\footnotetext{
1 In other words, "market" indices are often of limited interest for the typical investor, whose interest is focused on few specific segments. At the same time, the type of information required in the computation of specific indices is usually not available for other segments.

2 Obviously, the reliability of an index always depends positively upon the amount of information available.
} 
The paper is organised as follows. Section 2 presents the methodology used and introduces the indices. Section 3 illustrates the database and Section 4 outlines some of the results. Conclusions are in Section 5.

\section{The Methodology}

Artist and school indices based on averages of hammer prices usually do not control for changes in the artistic quality of the paintings sold in different periods. The lack of control for quality changes can lead to biased price indices whenever a single artist has produced paintings of different artistic values (in terms of materials, dimensions, techniques or artistic periods).

This consideration leads straight to the main point of the paper, which proposes a method aimed at reducing the consequences of the otherwise neglected paintings' heterogeneity among artists, techniques, materials used, subject, dimension etc.

We propose a bottom-up procedure, in which indices are computed for single artists and, at a different level of aggregation, also for schools and for the whole market. Contrary to what is done in the hedonic approach, we make no assumptions on the artistic structure of the single painting or artist; our maintained hypothesis rests instead on the adequacy of the price estimation in summarising all the relevant (artistic and economic) information, as "auctioneers do seem to provide genuine expertise in predicting prices [...] Perhaps honesty is an auctioneer's most profitable policy rule"13.

Our indices describe how an artist value changes over time, but do not identify the artistic factors which explain the price of the painting. This methodology is flexible enough so that it could be applied to build several indices: for artists, for (exogenously given) creative periods, or to compute a single index for several littleknown artists that could be better described by the school they are assumed to belong to.

To describe our methodology, let us consider an artist who sells at time $\mathrm{t}$ a number $\mathrm{N}_{\mathrm{t}}$ of paintings at auction. One can compute the average auction price of the artist as $p_{t}$ $=\Sigma_{\mathrm{i}}\left(\mathrm{p}_{\mathrm{it}}\right) / \mathrm{N}_{\mathrm{t}}$ with $\mathrm{i}=1,2, \ldots, \mathrm{N}_{\mathrm{t}}$. The ratio between the average price $\mathrm{p}$ in period $\mathrm{t}$ and

\footnotetext{
${ }^{3}$ See Ashenfelter, 1989. The maintained hypothesis of the repeat sales approach is the lack of difference in the price behaviour for all paintings sold once, twice or more times. The maintained hypothesis of the hedonic approach is the existence of a common, stable and identifiable set of hedonic regressors for all paintings.
} 
the average price in $t_{0}$, the first period of observation, is the (quality unadjusted) average Price Index, PI for that artist:

$$
P I_{t}=\frac{p_{t}}{p_{t_{0}}}
$$

As argued, such a simple average price index is not able to tackle the main evaluation problem in the market, the transaction of paintings of different quality in different periods. In the cases of high variability in the artistic (and possibly monetary) value of the production of a single artist, the lack of the adjustment for artistic quality changes becomes a critical point ${ }^{4}$.

In fact, a bias can arise in PI-type indices, which do not control for quality changes: if, at time t, a high (low) quality - high (low) valued painting is sold, the index increases (decreases) even if this painting has been sold at a low (high) price relatively to the average price for paintings of that quality, which can be approximated by the estimated price ${ }^{5}$. If high quality paintings enter the market more frequently when, on average, prices are high relatively to estimates, price ad quality changes are positively correlated and quality unadjusted indices tend to overreact with respect to the "true" price dynamics, thereby signalling an artificial increase in prices volatility. Often the quality effect might override the price effect. Therefore, PI is reliable only when the average quality of paintings is constant over time, which is usually not the case; notwithstanding, PI -type indices has been widely used in the literature.

To address the issue of heterogeneity, our main assumption is that the estimated price of a painting provides all the relevant information about its quality; in particular, we assume that at any given period t two paintings differ in their estimates because of their quality. ${ }^{6}$ The average estimated price of those $\mathrm{N}_{\mathrm{t}}$ objects sold by a given artist at time $t$ can be computed as $e_{t}=\Sigma_{i}\left(e_{i t}\right) / N_{t}$ with $i=1,2, \ldots, N_{t}$ where $e_{i t}$ is the estimated price of the $i$-th painting and the ratio $p_{t} / e_{t}$ adjusts for quality and indicates whether or not the price effect at time $t$ is strong.

\footnotetext{
${ }^{4}$ It is well known that this problem is exacerbated when a limited number of observations is available for an artist in each period of time.

${ }^{5}$ Estimated prices are assumed to signal correctly the true value of the art piece, in line with Ashenfelter and Graddy (2002). In some case estimates are found to differ systematically from auction prices; see Bauwens and Ginsburgh (2000) and Ekelund, Ressler and Watson (1998).

${ }^{6}$ We are not interested in the reason why this occurs. As suggested by the hedonic approach, the lower quality might stem from the subject it represents, the technique used, the period in which it has been painted. Moreover, quality changes also with respect to the different genre, i.e., paintings and drawings. In every case the market value of the art object's characteristics is summarised by its estimated price.
} 
At this stage, if inflation was zero and the estimation criteria of the auction house were constant over time, inter-temporal comparisons would be possible: from the case $e_{t+\tau}>e_{t}$, we could conclude that the estimated quality of the art work sold in period $t+\tau$ is higher than the estimated quality in period $t$. Therefore, the Price to Estimate Index (PEI), reported in [2] could be used:

$$
P E I_{t}=\frac{p_{t} / e_{t}}{p_{t_{o}} / e_{t_{o}}} .
$$

However, this price index should be adjusted to take into account also the market dynamics and the inflation process.

First, if the market is bull, it is likely that the estimated prices are revised upward over time by the experts, since these values also represent selling expectations. In other words, the estimated price would track the market trend. If this effect is not neutralised, $e_{t}$ increases as a consequence of the market dynamics and the ratio $p_{t} / e_{t}$ would underestimate the "true" price dynamics. The opposite would happen if the market were bear. In our framework, experts have no informational advantage over the market, and all the deviations of the realised prices from the estimates are unpredictable. ${ }^{7}$ Moreover, because are revised after these unpredictable deviations occur, estimates should follow a random walk. The ratio of the average price to the average estimate therefore represents a proxy of the price trend for the artist (neutralised for idiosyncratic shocks).

Second, the effect of inflation has to be considered. Estimated prices tend to increase over time simply because of the increase in the general price level.

Let us therefore define $\mathrm{me}_{\mathrm{t}}$ as the average estimated price of the whole market at time $\mathrm{t}, \mathrm{mp}_{\mathrm{t}}$ as the average market price, and $\pi_{\mathrm{t}}$ as a price index, like the CPI. We try to take into account the two factors mentioned above, computing the adjusted estimated price $a e_{t}$ by filtering the estimated price $e_{t}$ with (three-year) moving averages $^{8}$ :

\footnotetext{
${ }^{7}$ We assume that all the information is available only at the end of the year; therefore there is no adjustment in the expectations within the period. Obviously, this simplification is more realistic in the first months of each year.

${ }^{8}$ We have tested various adjustment procedures for estimated prices, based on the geometric mean and on moving averages of different lengths. The former adjustment, unsurprisingly, implies a much more nervous increase (or decrease) in the index when $\mathrm{p} / \mathrm{ae}$ is constantly higher (lower) than 1 for successive years; therefore, we rule out this procedure. Moving
} 


$$
a e_{t}=\left(\frac{e_{t}}{\pi_{t}}\right) /\left(\frac{1}{3} \sum_{j=t-3}^{t-1} \frac{m p_{j}}{m e_{j}}\right)
$$

In our guess the adjusted estimated price $a e_{t}$ can be considered the average estimate that would have been registered if the $\mathrm{N}_{\mathrm{t}}$ objects had been sold at time $\mathrm{t}_{0}$ rather than at time $\mathrm{t}$; therefore $\mathrm{p}_{\mathrm{t}} / \mathrm{ae}_{\mathrm{t}}$ represents the artistic quality and market adjustment in the value of the artist's work sold in period t. Obviously, the adjustment is different in the first three periods of the sample: in the first year there is no adjustment with respect to previous observations and $\mathrm{ae}_{0}=\mathrm{e}_{0}$, in the second year a $\mathrm{MA}(1)$, in the third year a $M A(2)$ and from the fourth period onwards a $M A(3)$ is used.

The resulting API (Artist Price Index) in which the auction prices in periods $t_{0}$ and $t$ are weighted by the average of the adjusted estimated prices at time $t_{0}$ and $t$

$$
A P I_{t}=\frac{p_{t} / a e_{t}}{p_{t_{0}} / a e_{t_{0}}}
$$

is an index adjusted for quality, market dynamics and inflation ${ }^{9}$. Since $p_{1} / a_{1}, p_{2} / a e_{2}$ ,$\ldots$ are "real" prices, in order to obtain the API we divide all terms by $\mathrm{p}_{0} / \mathrm{ae}_{0}$. As we attempt to control for the changes in the quality of art works sold at auction, API does not rise (fall) if a relatively high (low) valued object is sold (as the PI); on the contrary, it rises if a painting of any given value (low or high) is sold at an auction price higher (lower) than its estimated price, adjusted for market dynamics and inflation.

Another way to look at the rationale of the index is that it attempts to capture the pattern of change in the estimated price $e$ with respect to its value in period $t_{0}$. Neglecting the quality heterogeneity issue (for example, for a given artist is auctioned always the same painting), assume for the moment a constant "quality" in periods $\mathrm{t}=0,1,2, \ldots$ If the pre-sale estimates were correct, we might use PI, since the "weights" $e_{t}$ would not change over time (and therefore would cancel out in the computation of the index). For period $t=1$, for example, $e_{1}=e_{0}$ :

$\left(p_{1} / e_{1}\right) /\left(p_{0} / e_{0}\right)=p_{1} / p_{0}=P I_{1}$

averages of different length give essentially equivalent results; our 3-year lag depends on the short-time horizon of the data set (twelve years) on which we test the index.

${ }^{9}$ Clearly, API is a "nominal" index, in the sense that it considers un-deflated auction prices. We can compute a "real" index by deflating them. 
Then assume that over time the quality of the painting (and the estimate) was subject to temporary changes around the market price $p: e_{1}=p_{1} z_{1}$ where $z_{1}$ is a white noise with mean equal to one. Therefore:

$$
\mathrm{p}_{0} / \mathrm{e}_{0}=1 / \mathrm{z}_{0} ; \quad \mathrm{p}_{1} / \mathrm{e}_{1}=1 / \mathrm{z}_{1}
$$

and, rather than using $p_{0} / e_{0}, p_{1} / e_{1} \ldots$ as index, which would not be correct since the weights $e_{t}$ change randomly every period, the series $p_{0} / e_{0}, p_{1} / e_{0}, \ldots$ would be used instead. Then $p_{1} / e_{0}=\left(p_{1} / e_{1}\right)\left(e_{1} / e_{0}\right)=\left(1 / z_{1}\right) F\left(z_{0}\right)$, where $F\left(z_{0}\right)$ is the adjustment factor of the estimate, which argument is the surprise in the price to estimate ratio in period $t=0$. If the surprise was temporary there would be no adjustment, $F\left(z_{0}\right)=e_{1} / e_{0}$ $=1$, and the index would be a white noise process.

On the contrary, if part (at least) of the surprise is expected to persist over time, perhaps because the perceived quality of the painting auctioned has changed, then $\mathrm{e}_{1} / \mathrm{e}_{0}=\mathrm{F}\left(\mathrm{z}_{0}\right) \neq 1$ and the index would not be a white noise. We try to capture this latter effect by averaging market surprises over the whole market and over time. As the distinction between temporary and permanent changes are unobservable, in period $t$, if $z_{t}$ has been lower than one (prices lower than estimates), the estimate is likely to be revised downward in period $t+1$, accordingly to past market outcomes.

A few further remarks might be of interest. First, if in period t, paintings of the same author have been sold in different countries, the computation of the index requires the conversion into a single currency of all transactions. Obviously, the use of a single currency influences the dynamic of the index. Since the data on the residence of the buyers are not available, a prevalence criterion should be used. Therefore, we have computed three series of indices based on the US dollar, the Euro and the UK pound, respectively ${ }^{10}$. Although subject to more pronounced fluctuations, the nominal exchange rate conversion is probably to be preferred to the Purchasing Power Parity adjustment as the transaction of art works, and paintings in particular, is analogous to the exchange of financial assets, in which the speculative motive and the expectations about future values can provide useful insights into the understanding of the type and the timing of transaction.

\footnotetext{
10 Almost all the main transactions of art in auctions around the world are denominated in these three currencies. Due to space constraints, we present only the US dollar indices, which express the point of view of an operator whose reference currency is the US dollar; however, the influence of the currency on the indices is limited. The Euro and UK pounds indices are available upon request from the authors.
} 
Second, the API index (as well as other financial indices) does not exhaust the economic evaluation of the artist, as its relevance depends upon the number of the paintings presented and sold in auctions. For example, for a given artist the absolute number of paintings auctioned (sold and unsold) and the percentage of paintings sold at any period might contribute to measure its "liquidity" on the market, and are likely to influence its estimates in the following periods.

Third, since the process of adjustment of estimated prices uses market averages of paintings from all the artists, even the less frequently traded, it might be claimed that the inclusion of marginal artists in the computation might bias the indices of the leading artists. However, there is no a priori reason to exclude these artists from the analysis, although a well developed market does not exist for them.

\section{Data-set and model design.}

The computation of the indices is based on a dataset provided by Gabrius S.p.A. which gathers more than 330000 observations of art paintings sold world wide in auctions by the major auction houses since 1990. Each observation includes, among other variables, the name of the artist, the title of the painting, the date, city of sale and the auction house, the price (when the painting is sold) and a low and a high estimate. Only the paintings whose estimated value is equal or greater than 2500 dollars, at constant 1995 prices are entered the database ${ }^{11}$. The implicit assumption behind this selection is the existence of a form of segmentation in the art market in terms of monetary values: the medium or high quality - medium or high price segment which is tracked by the date base leads, and the low quality - low price segment of the market follows.

Following the usual division made by art experts, for our purposes it is convenient to distinguish three different segments: old masters paintings (OMP), $19^{\text {th }}$ century paintings ('800), and modern and contemporary paintings ('900). This implies that three different averages are computed for prices and estimates, that is, $\mathrm{mp}$ and $\mathrm{me}$ in formula [3] are defined for each segment. The database includes the 24 most important auction houses operating in 54 market places. The most frequent auction houses are Sotheby's and Christie's with almost $40 \%$ of transaction for each segment.

\footnotetext{
11 The value is reduced to 1000 USD for modern and contemporary paintings. In addition, only objects for which a picture appears in the catalogues are included in the database. Further information on the data bank can be obtained at http: IIwww.gabrius.com.
} 
With respect to market places, London (with $33.9 \%, 34.8 \%$ and $19.3 \%$ for the OMP, '800 and '900 respectively) and New York (with 15.7\%, 23.6\% and 31.8\% respectively) are, unsurprisingly, the most frequent in the database. With respect to the currency in which the auction price is denominated, 10 currencies are included in the database, but the transactions are mainly carried out in UK pounds and US dollars in the $43.8 \%$ and $18.1 \%$ respectively in the OMP, in the $42.9 \%$ and $28.9 \%$ in the $' 800$ and in the $31.2 \%$ and $37.6 \%$ in the ' 900 (in terms of number of transactions).

\section{INSERT TABLE 1 ABOUT HERE}

Table 1 shows the average estimated price (me) and the average auction price $(\mathrm{mp})$ for the whole market. It is apparent the changing importance of the quality and price effects over the period considered. For example, in Modern and Contemporary art both me and $\mathrm{mp}$ are higher in 1990 relatively to 1991. This change in prices can be inputted to a drop in the average quality of the objects sold (possibly due to a selection bias in the data set) but also to the change from a bull to a bear market. In the former case $\mathrm{mp} / \mathrm{me}$ would be unaffected. A rough empirical evaluation suggests that this is not the case. For the OMP and ' 800 segments the correlation between $\mathrm{mp}$ and $\mathrm{mp} / \mathrm{me}$ is positive (about 0.7 and 0.4 , respectively). This means that higher quality paintings command higher prices to estimates ratios, with respect to low quality paintings, so that the quality adjustment ae embodied in API as in formula [2] correctly tackle this issue. For the modern and contemporary paintings the correlation is strong and negative (about -0.4), possibly because of the different market strategies of the auction houses and the collectors. In any case, emerges a systematic linkage between the two series.

All values were converted in US dollars at the average monthly rate; to deflate monetary values we used the US consumer price index (CPI). We computed the estimated price as the simple average of the two estimates (minimum and maximum) included in the database. This choice, although supported by the intuition, is arbitrary, since we do not develop any behavioural model about the underlying mechanism of formation of the estimated price ${ }^{12}$.

\footnotetext{
12 Ashenfelter and Graddy (2002) explain the spread in the estimates as a measure of uncertainty, since both values originate from a single guess plus or minus the expected price variance. Several tests have been run to evaluate the robustness of the indices to the use of
} 
An important issue in the computation of the API index concerns the evaluation of the unsold paintings, since its percentage with respect to total paintings auctioned is not negligible, about $40 \%$ of the total number of observations ${ }^{13}$. The reserve price of the sellers might approximate the implicit re-purchasing price of the painting by the owner, and could be used in the computation of the indices. However, this information is not known and in order to avoid arbitrary and un-testable assumptions about these reserve prices (like adjustments in which the reserve price is a fixed percentage of the estimated price ${ }^{14}$ ) we delete all no-sale cases, even if this choice eliminates a relevant part of the database. The number of artists included remains high, as shown in Table 1: 6587 artists in the Old Masters, 9829 in the $19^{\text {th }}$ Century and 7869 in the Modern and Contemporary Paintings databases, respectively.

\section{The Artist Price Indices}

Table 2 shows the number of years in which each artist is found in the database. The great majority of the artists is met only in a limited number of years, and only a small percentage of artists ( $12 \%$ in the Old Masters, $5.3 \%$ in the $19^{\text {th }}$ Century and $7.9 \%$ in the Modern and Contemporary Paintings) sells in at least 10 years out of the 12 for which data are available. In the OMP segment, 168 artists with at least 100 paintings auctioned can be identified; among them, there are 78 artists with at least 100 paintings actually sold. For the $19^{\text {th }}$ Century there are 184 and 82 artists with at least 100 paintings auctioned and sold, respectively. For the Modern and Contemporary Paintings segment the relevant figures are 336 and 194, respectively.

\section{INSERT TABLES 2 AND 3 ABOUT HERE}

It is possible to compute 25004 index-numbers in the Old Masters, 27629 in the $19^{\text {th }}$ Century and 24594 in the Modern and Contemporary Paintings. For most of the artists the transactions are recorded only for a few years; for each artist it is possible to

\footnotetext{
estimated prices computed by using weighted averages of minimum and maximum estimates. Ekelund et al. (1998) and Picci and Scorcu (2003) provide some further empirical support for this proposition.

13 It is well known that not all of what is unsold in the auction is actually no-sale; a painting can be transacted once the auction is over.

${ }^{14}$ Ekelund et al. (1998) suggest that the reserve price is linked to the low estimate of the painting; see also Ashenfelter and Graddy (2002).
} 
compute on average 3.8 index-numbers in the Old Masters, 2.8 in the $19^{\text {th }}$ Century and 3.1 in the Modern and Contemporary Paintings. Whereas for most of the artists it is not possible to compute a long series of the price index, we are able to identify a group of artists whose indices can be considered reliable ${ }^{15}$, artists which are likely to represent the backbone of the market.

Table 3 shows the actual coverage of the proposed methodology, identifying the number of artist-indices in each year. According with the number of observations included in the database, 2000 and 2001 are the years with the higher number of indices (for 2001 there are 3440, 2469 and 2146 yearly, author specific indices available for Modern and Contemporary Paintings, $19^{\text {th }}$ Century and Old Masters databases, respectively).

As API is adjusted for the quality of the paintings sold, we expect it to remain closer to unity, the initial value of the series in the first year of presence of the artist, and to exhibit lower volatility than PI-type indices. In fact, the average value of the API (PI) indices is $1.33(1.88)$ in the Old Masters, $1.16(1.43)$ in the $19^{\text {th }}$ Century and 1.14 (1.28) in the Modern and Contemporary Paintings. This means that on average high quality paintings command higher estimates, but also higher prices, than low quality paintings, so that the quality adjustment embodied in the price to estimate ratio reduces, on average, the value of the index. The average standard deviation for the API index is 0.82 in the Old Masters, 0.71 in the $19^{\text {th }}$ Century and 0.78 in the Modern and Contemporary Paintings, lower than the corresponding values of the PI indices (2.74, 4.90 and 9.02, respectively), thus showing more stability and less erratic trends.

Also a simple test of correlation shows that the API and the PI indices measure the behaviour of the market for paintings from different perspectives: the correlation coefficient between these (aggregate) indices is 0.191 in the Old Masters database, 0.268 in the $19^{\text {th }}$ Century and 0.133 in the Modern and Contemporary Paintings (the coefficients are all significant at the $1 \%$ level). Finally, a systematic relationship between API and the percentage of sold paintings does not emerge, as the correlation coefficients are -0.01 for the Old Masters and for the Modern and Contemporary Paintings and -0.04 for the $19^{\text {th }}$ Century.

\footnotetext{
15 Obviously the reliability of the index depends on the number and type of paintings sold by the artist, but also on the temporal distribution. As a rule of thumb we do not consider a priori unreliable the index of an artist which sells at least 4-5 paintings each year and for which there are no two consecutive years of absence in the database.
} 
In Figures 1 to 3 we compare the dynamics of the nominal and real API indices with PI index for one artist of each segment of the paintings market. As for the Old Master, in Figure 1 the indices for "II Veronese" show that the trend of the API can be quite different from the trend of the (quality unadjusted) PI. Figure 2 plots indices for Carl L. F. Becker; the greater stability of the API with respect to PI has to be stressed: in both 1996 and 1999 the unadjusted price index reaches the outstanding values of 16.83 and 8 respectively. These values, however, are not the result of good performances reached by the artist on the market but rather the result of the sale of particularly high valued paintings which, at least in 1999, have not been sold to particularly good prices, if compared to their pre-sale estimates. Finally, the indices of George Braques are plotted in Figure 3 for the Modern and Contemporary Paintings segment. Again, the greater stability of the API indices must be emphasised.

Another possible comparison is the one between the API and the hedonic index computed through hedonic regressions. Following Chanel, Gerard-Varet, and Ginsburgh (1996) and Agnello and Pierce (1999) and we run the following hedonic model for few well-known artists, which appear in the data base with a considerable frequency:

$$
\begin{aligned}
& \text { Inp }=\beta_{0}+\beta_{1} \text { Indim }+\beta_{2} \text { lotpos }+\beta_{3} \text { lotpos }^{2}+\beta_{4} \text { namecity }+\beta_{5} \text { genre }+\beta_{6} \text { support } \\
& +\beta_{7} \text { material }+\beta_{8} \text { subject }+\beta_{9} \text { month }+\beta_{10} \text { year }+\varepsilon
\end{aligned}
$$

The dependent variable Inp is the logarithm of the auction price, Indim is the logarithm of the painting's dimension, lotpos and lotpos ${ }^{2}$ are the relative lot position in the auction and its squared term, respectively ${ }^{16}$, namecity is a series of dummies indicating the combination of place and house in which the auction was held, genre, support, material and subject are a series of dummies relative to the characteristics of the painting, month and year are a series of dummies indicating the month and the year in which the auction was held.

INSERT TABLE 4 ABOUT HERE

16 These variables are meant to capture any ascending or descending effect on the auction price of the sequential position in the sale. 
From this hedonic model it is possible to compute a Hedonic Price Index (HPI) by taking the exponential of the (time varying) coefficient of dummy year:

$$
\mathrm{HPI}=\mathrm{e}^{\beta 10} \quad \mathrm{t}=1991,1992,1993, \ldots
$$

If the base year is 1990, this series starts from on $\mathrm{e}^{17}$ and is comparable with API indices. In Table 4 the basic statistics of the hedonic model for the selected artists are reported. Whereas it is not the aim of the paper to discuss the hedonic methodology or the evidence resulting from applying this approach to our data base $\mathrm{e}^{18}$, we want to discuss in the remaining of this section the main issues resulting from a comparison between API and HPI.

\section{INSERT FIGURES 4-6 ABOUT HERE}

In Figures 4 to 6 the API and HPI indices for Marc Chagall, Andy Warhol and Pierre Auguste Renoir are reported ${ }^{19}$. Some results emerges neatly: (i) as already discussed, API has properties of smoothness and stability which stem from the fact that it fully embodies the perceived quality changes of the paintings transacted by adjusting for the estimated values; (ii) short run fluctuations are similar for API and HPI, even if API is based on moving averages; (iii) the long run trend of API and HPI are somewhat different, as API turns out to be a less pessimistic indicator of the art market crisis of the beginning of the 90s; as already discussed, when the market falls, it is more likely that estimates are revised downwards and less important paintings are auctioned. If those factors are taken into account through the estimates, as in API, one can conclude that the market has fully recovered since then.

The overall comparisons with indices based on different methodologies suggest that API might be a reliable price indicator of this market.

As already mentioned in Section 2, this methodology can be applied to different levels of aggregation. For example, if paintings are not divided by artists but by artistic schools, we can compute several school market indices or, at a more aggregate level,

\footnotetext{
${ }^{17}$ Clearly, the base dummy not included in the regression is the first year in the series, 1990, which implicit coefficient is 0 , thus implying that $\mathrm{HPI}_{1990}=1$.

18 See to this respect Candela et al. , 2002.

19 Other authors indices are available from the authors upon request. We have computed both series starting from 1990 and 1992 to check whether the market collapse of the beginning of the 90 s makes any difference to the indices. We have not found any significant difference, so that only the 1990 series are reported.
} 
a general market index. Figure 7, 8 and 9 show the indices for the three main segments of the market (OMP, '800 and '900). In all cases, after the negative trend in 1991-1992, a positive price trend emerges. A twelve year-investment in the art market from 1990 to 2001 would have given an overall nominal rate of return of $30.3 \%$ in the Modern and Contemporary Paintings, only $21.6 \%$ in the $19^{\text {th }}$ Century and $24.7 \%$ in the Old Masters segment, thereby confirming the well known findings of low, although positive, returns on these assets. ${ }^{20}$

\section{INSERT FIGURES 7-9 ABOUT HERE}

\section{Conclusions}

In this paper we develop an annual price index for artists based on estimates and auction prices. We compute this index by considering the ratio of the average market price to the average estimated price of the paintings sold by an artist each year. We adjust the average estimated price at a point in time on the basis of the previous dynamics of the price to estimate ratios, by assuming that if the market is bull (bear), estimated prices are likely to be increased (decreased) by experts. We use the same methodology to compute school and market indices.

We apply this methodology to a group of selected artists drawing from Gabrius' database including market and estimated prices of more than 300,000 paintings auctioned world wide between 1990 and 2001. Our quality-adjusted indices exhibit less volatility than quality unadjusted and hedonic price indices. Unsurprisingly, indices computed for artists who are commonly traded are less erratic, thus indicating that the reliability of the indices presented herein should be taken with some caution when the artist is not exchanged regularly in auctions.

The large database we currently avail allows us to shed some light on the movements of the market and of the leading artists in the last ten years; according to the Artist Price Indices, the crisis which affected the art market at the beginning of the 90s might have been less strong if artistic quality changes over time were taken into account.

\footnotetext{
20 On the long run rate of return to investment in paintings see Frey and Eichenberger (1995) and, more recently Pesando and Shum (1999). Ashenfelter and Graddy (2002) survey recent empirical studies on returns to art investment.
} 
Following the refinements of the method of computation of the indices, and the enlargement of the database, our future research will investigate the existence of long-run relationships between the performance of a single artist, the performance of the art market, the financial market and other economic variables.

\section{References}

Agnello, R.J., and Pierce, R.K., 1999, Investment Returns and Risk for Art: Evidence from Auctions of American Paintings (1971-1996), University of Delaware, Department of Economics, Working Paper 99/03.

Anderson, R.C., 1974. Paintings as an Investment. Economic Inquiry, 12:13-26.

Ashenfelter, O.C., 1989. How Auctions Work for Wine and Art, Journal of Economic Perspectives, 3(3):23-36.

Ashenfelter, O.C., and Graddy, K., 2002. Art Auctions: a Survey of Empirical Studies. CEPR Discussion Paper Series, No. 3387, CEPR, London.

Bauwens, L., and Ginsburgh, V., 2000, Art Experts and Auctions: Are Pre-sale Estimates Unbiased and Fully Informative?, Recherches Economique de Louvain, 66: 131-144.

Buelens, N., and Ginsburgh, V., 1993. Revisiting Baumol's Unnatural Value, or Art as Investment as a Floating Crop Game. European Economic Review, 37:1351-71.

Candela, G., Figini, P., and Scorcu, A.E., 2002. Hedonic Prices in the Art Market: a Reassessment, Presented at the ACEI Conference, Rotterdam, The Netherlands, June 2002.

Candela, G., and Scorcu, A.E., 1997. A Price Index for Art Market Auctions. Journal of Cultural Economics, 21:175-96

Chanel, O., 1995. Is the Art Market Behaviour Predictable? European Economic Review, 39:519-27.

Chanel, O., Gerard-Varet, L., and Ginsburgh, V., 1996. The Relevance of Hedonic Price Indices, J ournal of Cultural Economics, 20:1-24.

Ekelund, R., Ressler, R., and Watson, J., 1998. Estimates, Bias and No-Sales in Latin American Art Auctions, Journal of Cultural Economics, 22:33-42. 
Frey, B.S., and Eichenberger, R., 1995. On the Return of Art Investment: Return Analyses. Journal of Cultural Economics, 19:207-20.

Frey, B.S., and Pommerenhe, W.W., 1989. Muses and Markets: Explorations in the Economics of the Arts, Basil Blackwell, Oxford.

Goetzmann, W., 1993. Accounting for Taste: Art and Financial Market over Three Centuries. American Economic Review, 83:1370-76.

Pesando, J.E., 1993. Art as Investment: The Market for Modern Prints, American Economic Review, 83: 1075-89.

Pesando, J.E., and Shum, P.M., 1999. The Returns to Picasso's Prints and to Traditional Financial Assets, 1977 to 1996, J ournal of Cultural Economics, 23:182-92.

Picci, L., and Scorcu, A.E., 2003. Bidders' and sellers' strategies in sequential auctions. New evidence about the afternoon effect, Empirica, forthcoming.

Reitlinger, G., 1963. The Economics of Taste: the Rise and Fall of the Picture Market, 1760-1963. Holt, Reinhart and Winston, New York.

Reitlinger, G., 1970. The Economics of Taste: the Art Market in the 1960s. Holt, Reinhart and Winston, New York.

Stein, J.P., 1977. The Monetary Appreciation of Paintings, Journal of Political Economy, 85: 1021-35. 
Table 1 - Paintings, artists, prices and estimates, 1990-2001

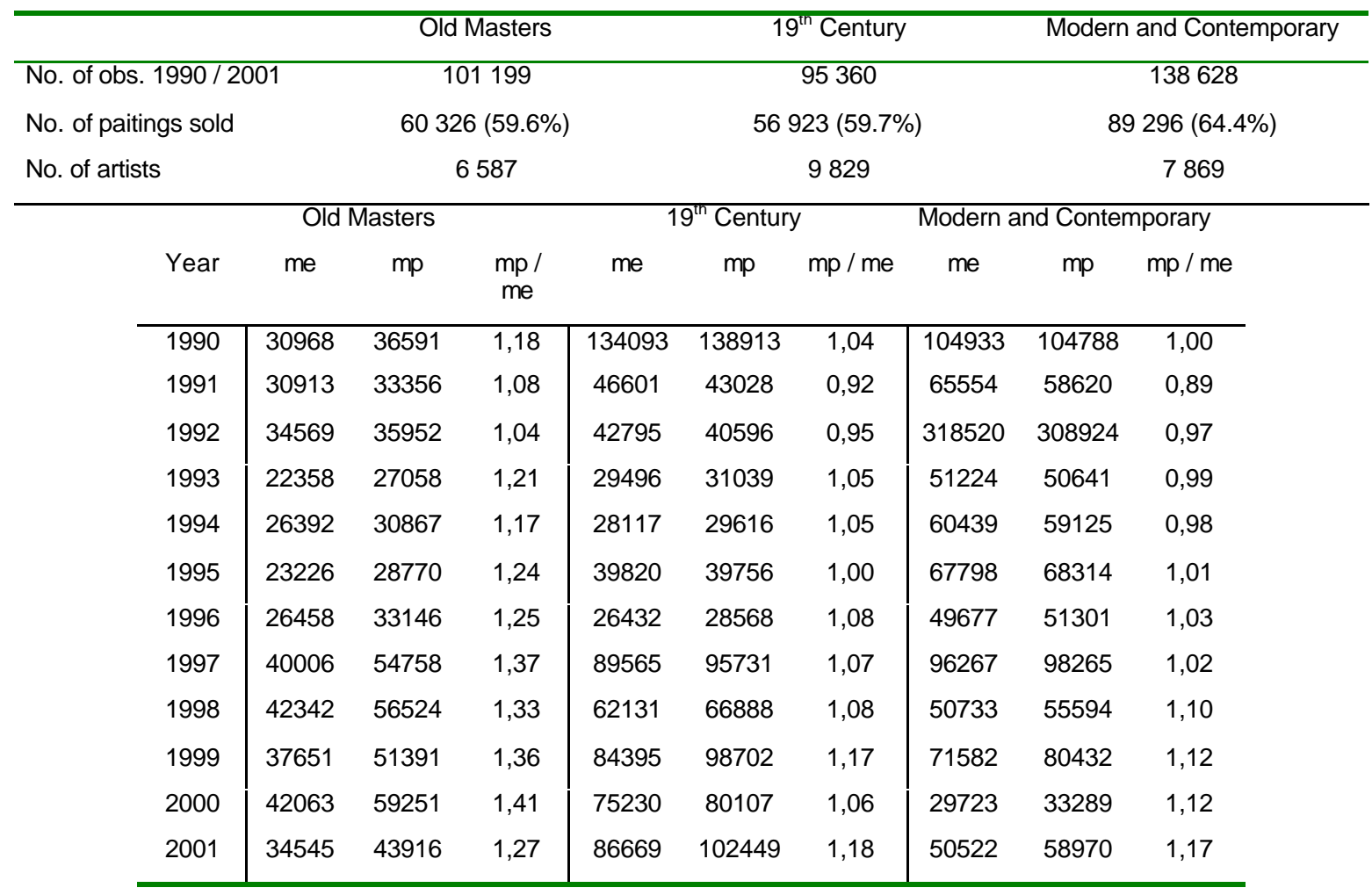

Table 2 - Presence of artists, 1990-2001

\begin{tabular}{cccc}
\hline $\begin{array}{c}\text { Years of presence } \\
\text { of the artist }\end{array}$ & Old Masters & $19^{\text {In }}$ Century & Modern and Contemporary \\
\hline 12 & 361 & 216 & 297 \\
11 & 226 & 156 & 178 \\
10 & 204 & 149 & 150 \\
9 & 198 & 171 & 162 \\
8 & 211 & 182 & 148 \\
7 & 248 & 246 & 195 \\
6 & 258 & 307 & 255 \\
5 & 315 & 416 & 335 \\
4 & 392 & 616 & 480 \\
3 & 600 & 873 & 733 \\
2 & 921 & 1635 & 1335 \\
1 & 2647 & 4839 & 3571 \\
\hline
\end{tabular}


Table 3 - Number of artist-indices, per year

\begin{tabular}{llcc}
\hline & Old Masters & $19^{\text {In }}$ Century & $\begin{array}{c}\text { Modern and } \\
\text { Contemporary }\end{array}$ \\
\hline 1990 & 2313 & 2328 & 2001 \\
1991 & 2034 & 1748 & 1569 \\
1992 & 1984 & 2155 & 1474 \\
1993 & 1951 & 2238 & 1284 \\
1994 & 2080 & 2200 & 1377 \\
1995 & 2090 & 2431 & 1585 \\
1996 & 2043 & 2526 & 1727 \\
1997 & 1951 & 1749 & 1458 \\
1998 & 1972 & 2312 & 2261 \\
1999 & 2238 & 2627 & 2949 \\
2000 & 2242 & 2846 & 3469 \\
2001 & 2146 & 2469 & 3440 \\
\hline
\end{tabular}

Table 4 - Hedonic model for selected artists

\begin{tabular}{lccccc}
\hline \multicolumn{1}{c}{ Artist } & $\mathrm{R}^{2}$ & adj. $\mathrm{R}^{2}$ & $\mathrm{~F}$ & observations & variables \\
\hline Renoir & 0.76 & 0.73 & 26 & 634 & 71 \\
Fontana & 0.78 & 0.75 & 24 & 535 & 71 \\
Chagall & 0.87 & 0.86 & 65 & 806 & 78 \\
Picasso & 0.80 & 0.79 & 71 & 1663 & 89 \\
Mirò & 0.77 & 0.74 & 24 & 636 & 78 \\
Appel & 0.68 & 0.63 & 14 & 546 & 73 \\
Warhol & 0.59 & 0.56 & 19 & 1048 & 74 \\
Calder & 0.86 & 0.84 & 50 & 568 & 63 \\
Dubuffet & 0.79 & 0.76 & 31 & 628 & 67 \\
Moore & 0.80 & 0.72 & 11 & 273 & 72 \\
\hline
\end{tabular}


Figure 1 - OMP Artist: Price Indices for II Veronese

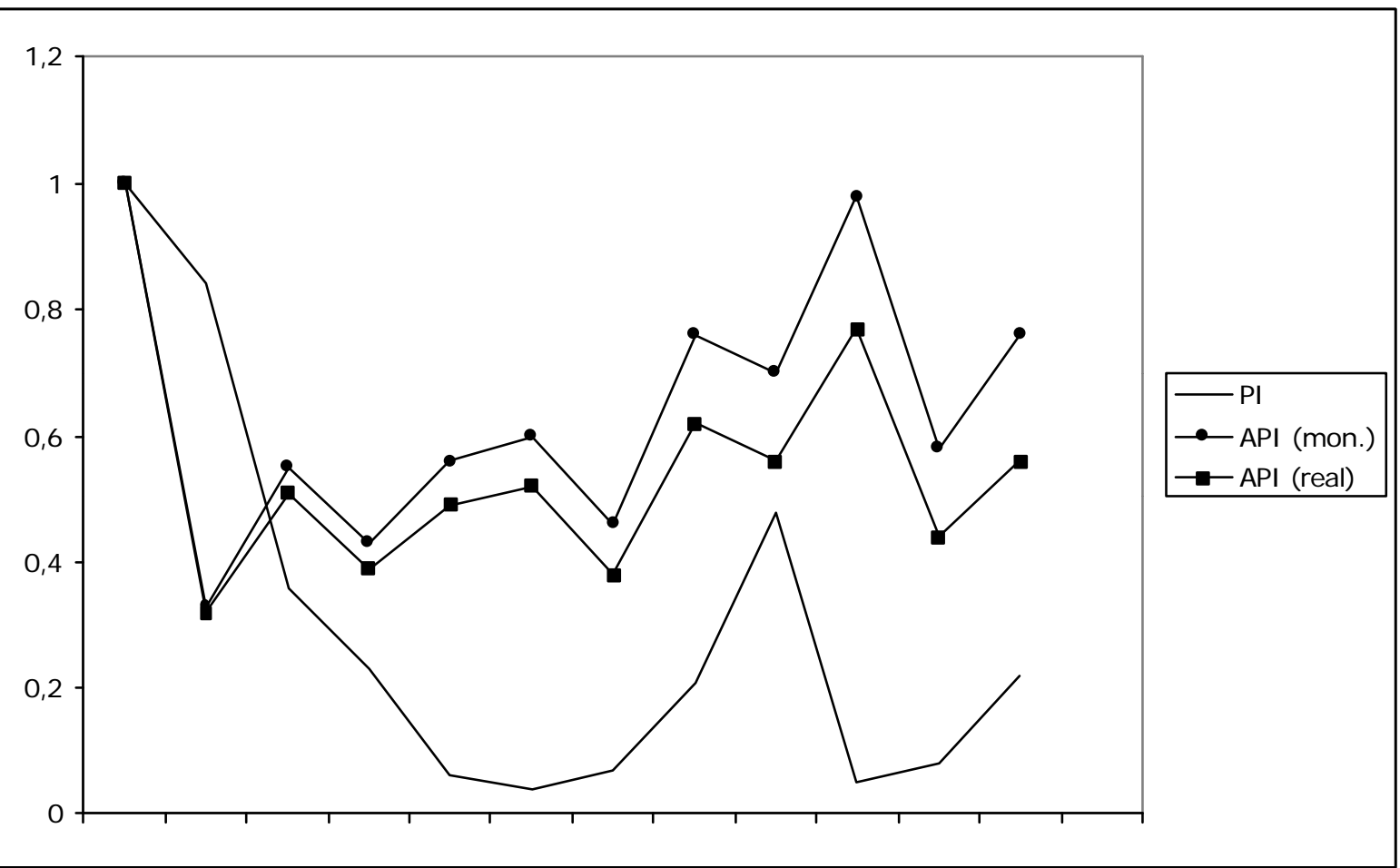

Figure $2-19^{\text {th }}$ Century Artist: Carl L. F. Becker

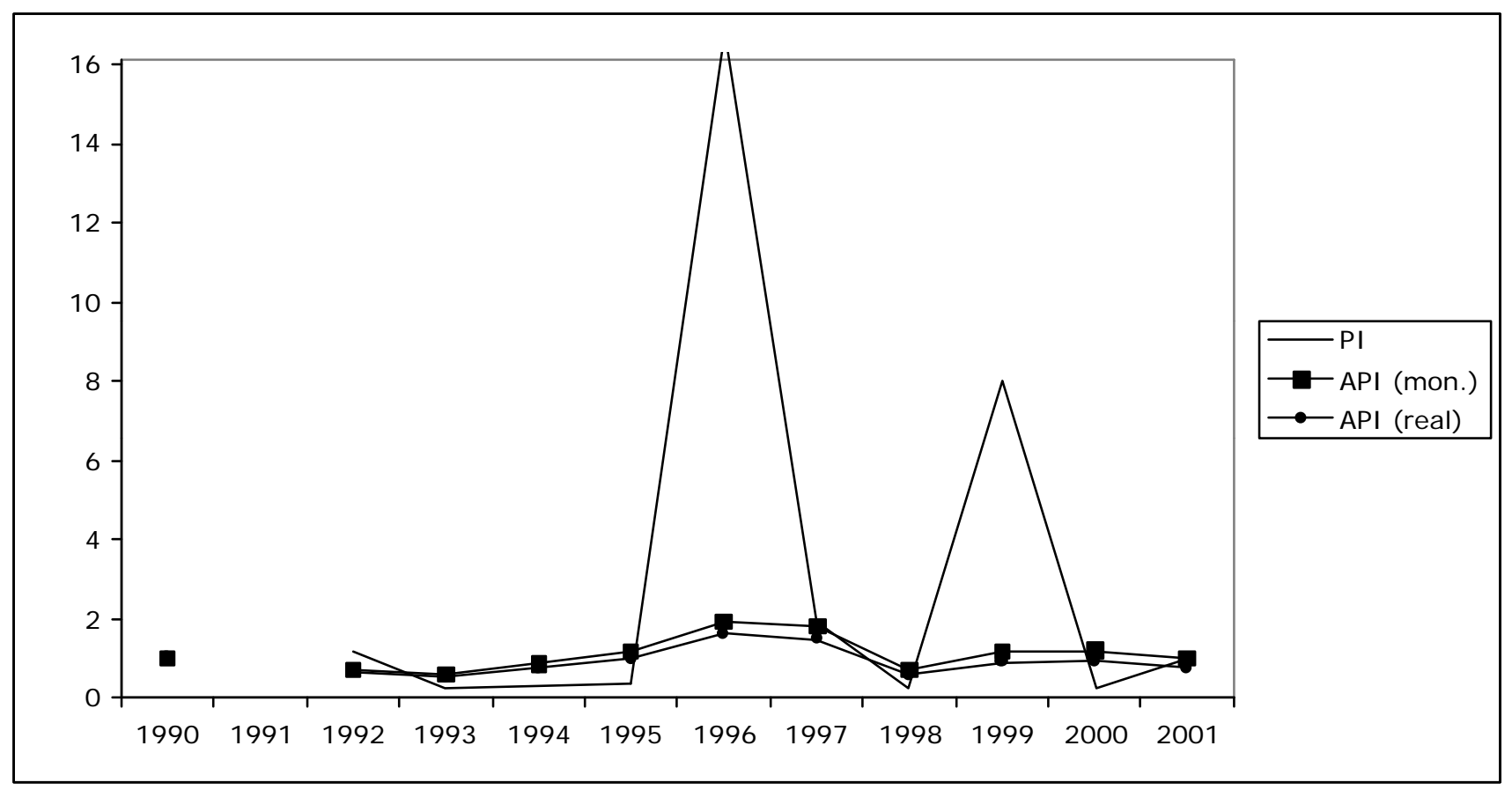


Figure 3 - Modern and Contemporary Artist: George Braques

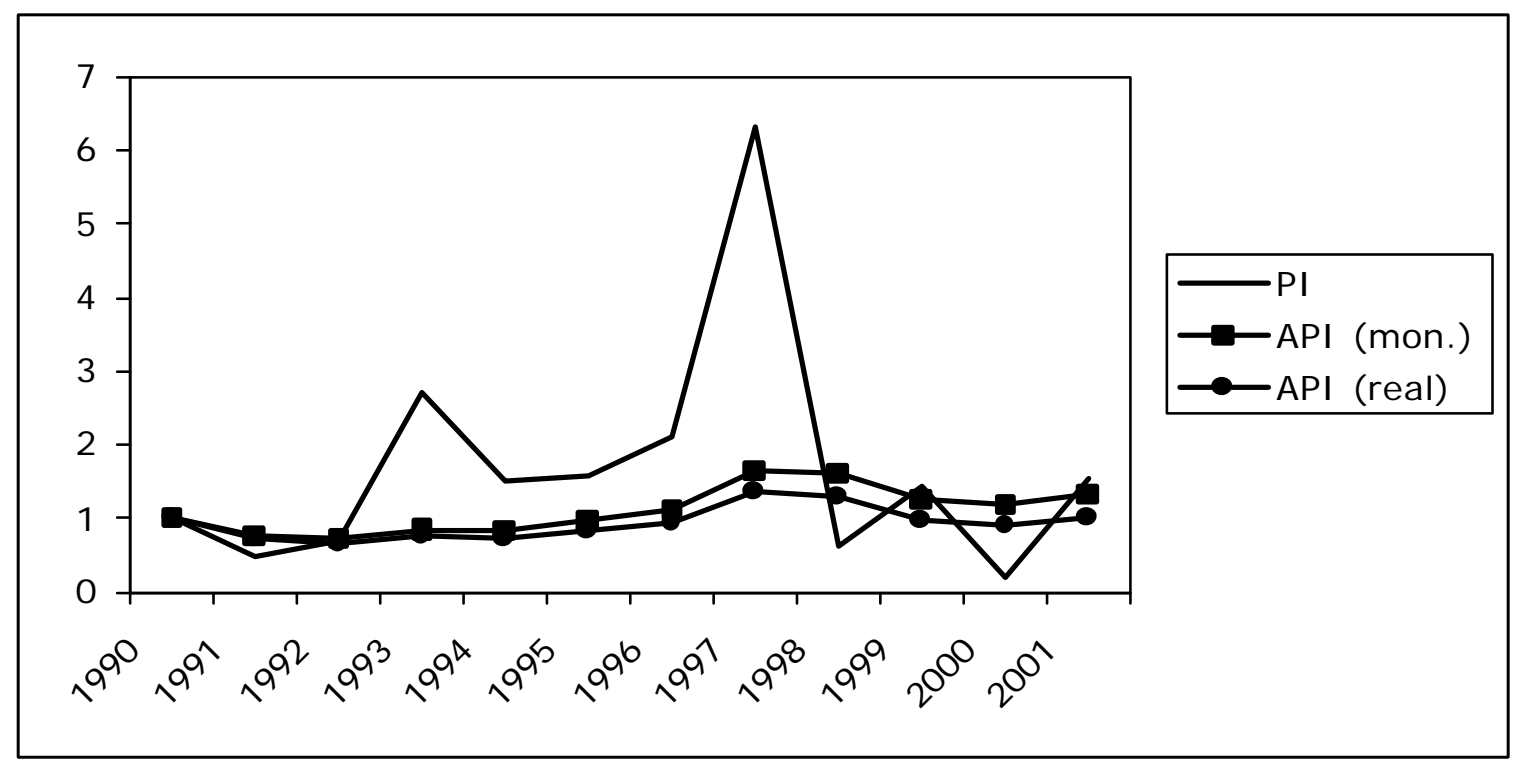

Figure 4 - Marc Chagall API and HPI indices

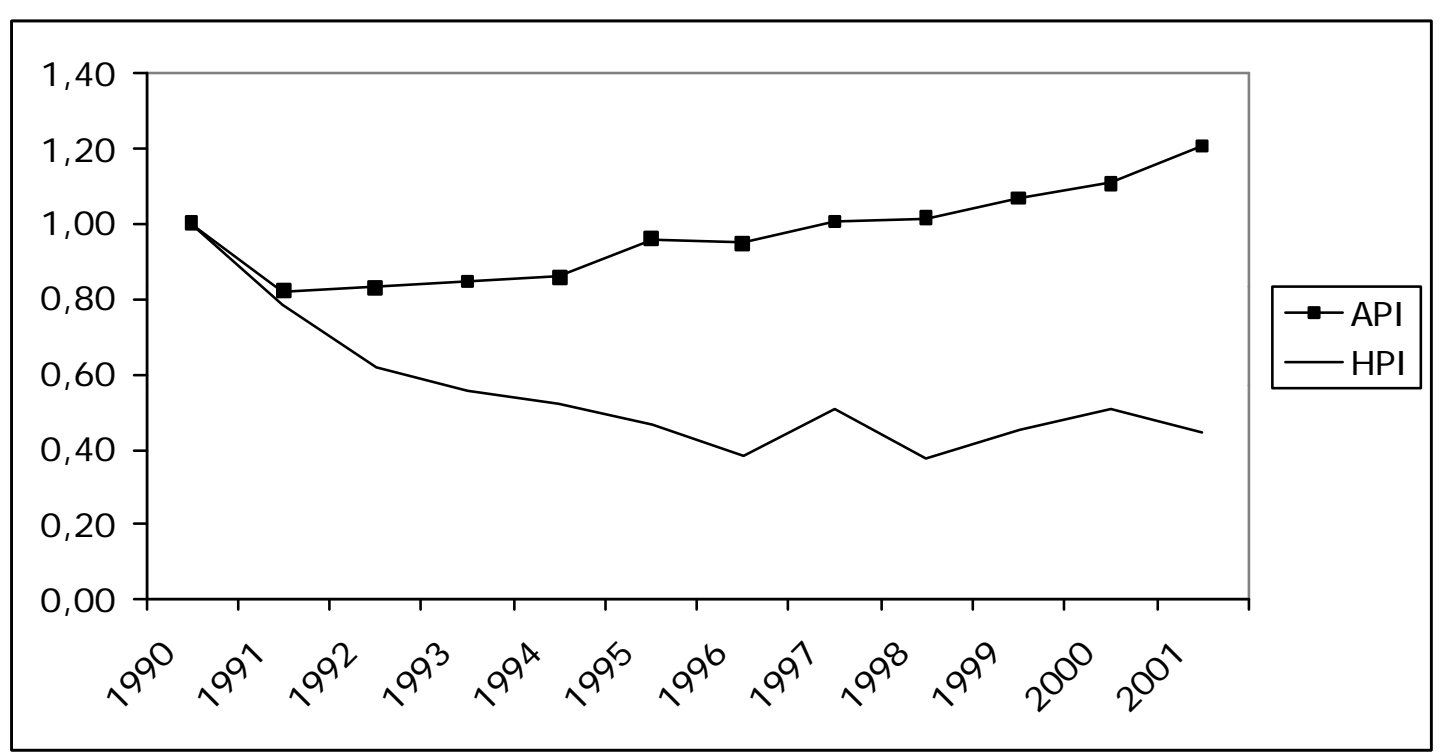


Figure 5 - Andy Warhol AMI and HPI indices

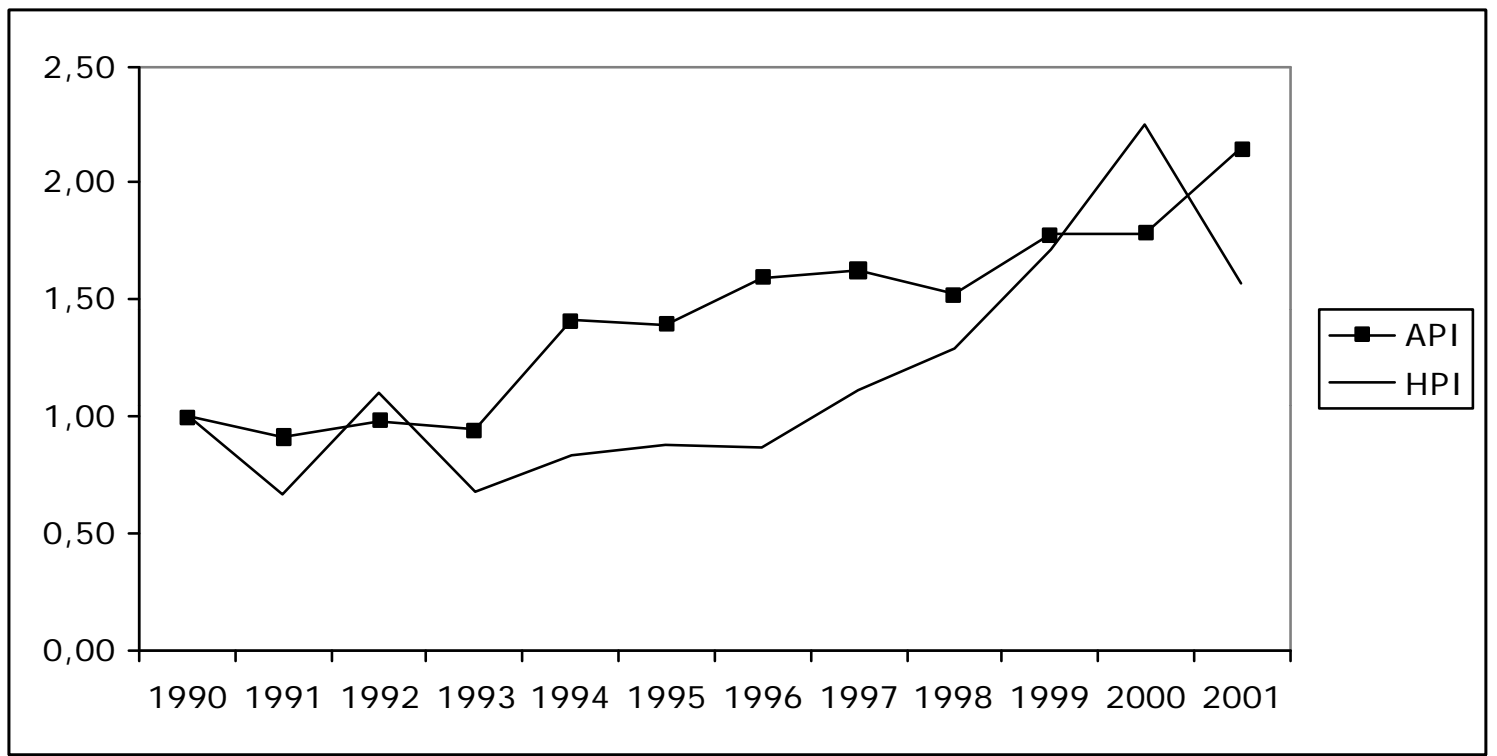

Figure 6 - Pierre Auguste Renoir AMI and HPI

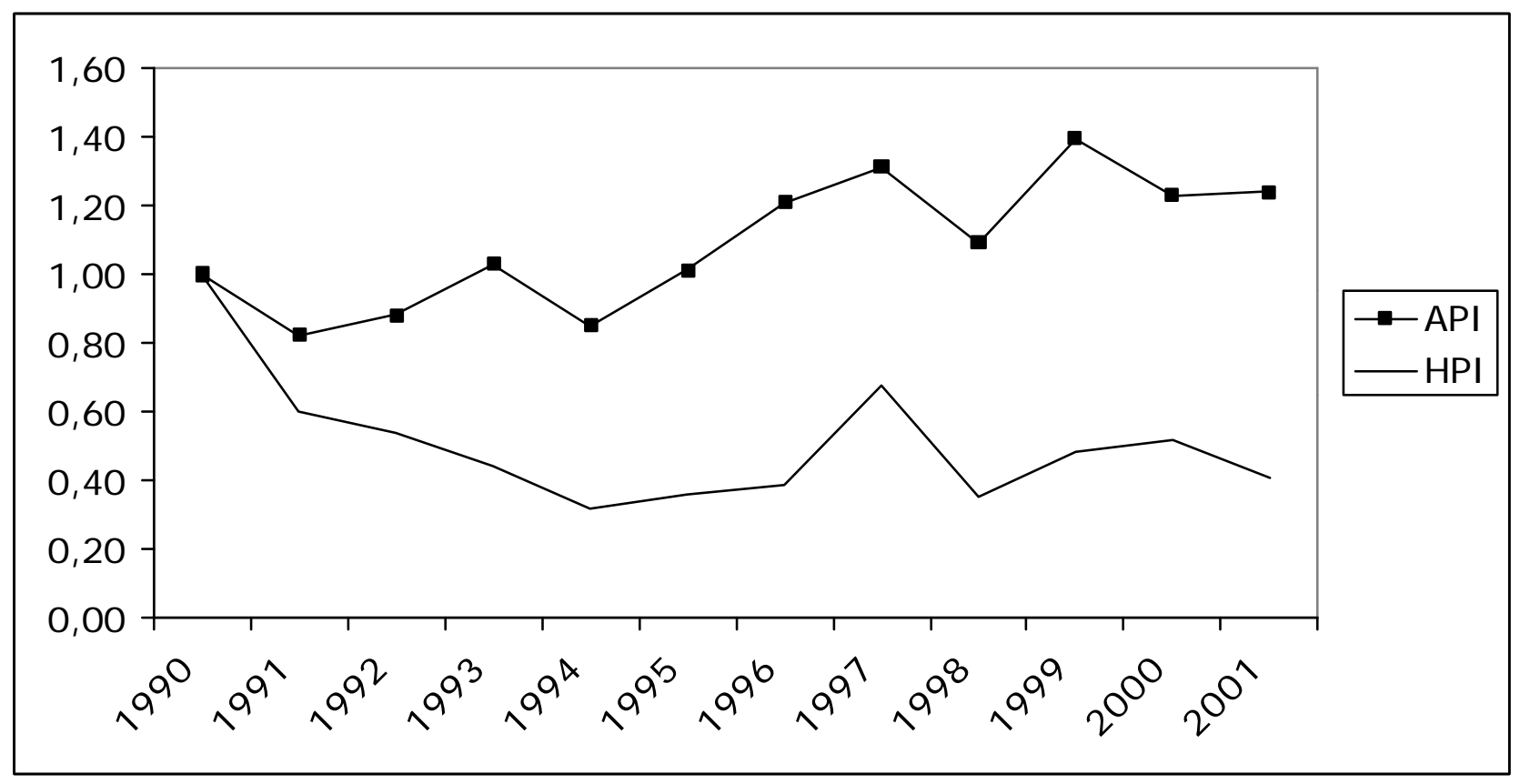


Figure 7 - Old Masters Market Index

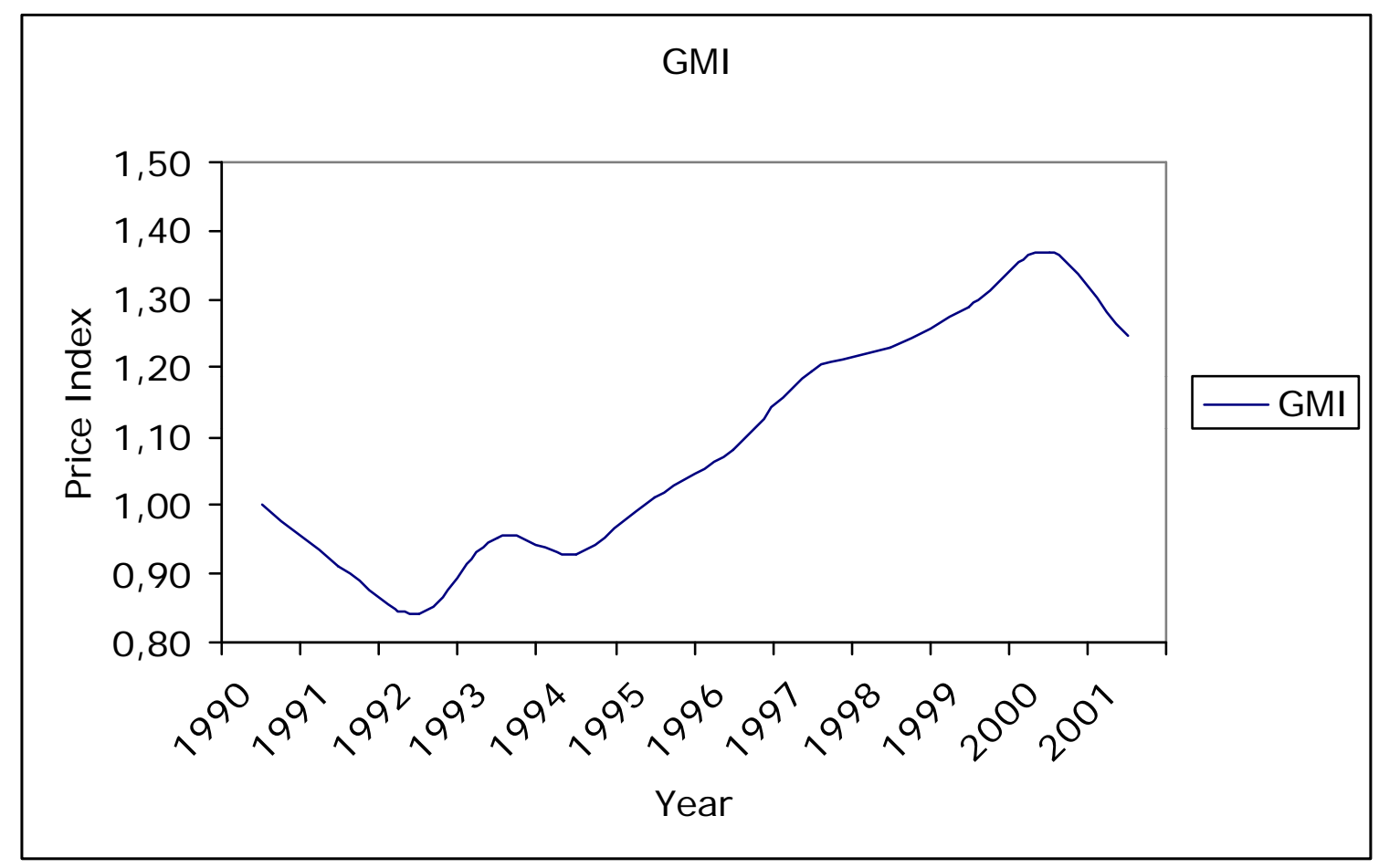

Figure $8-19^{\text {th }}$ Century Market Index

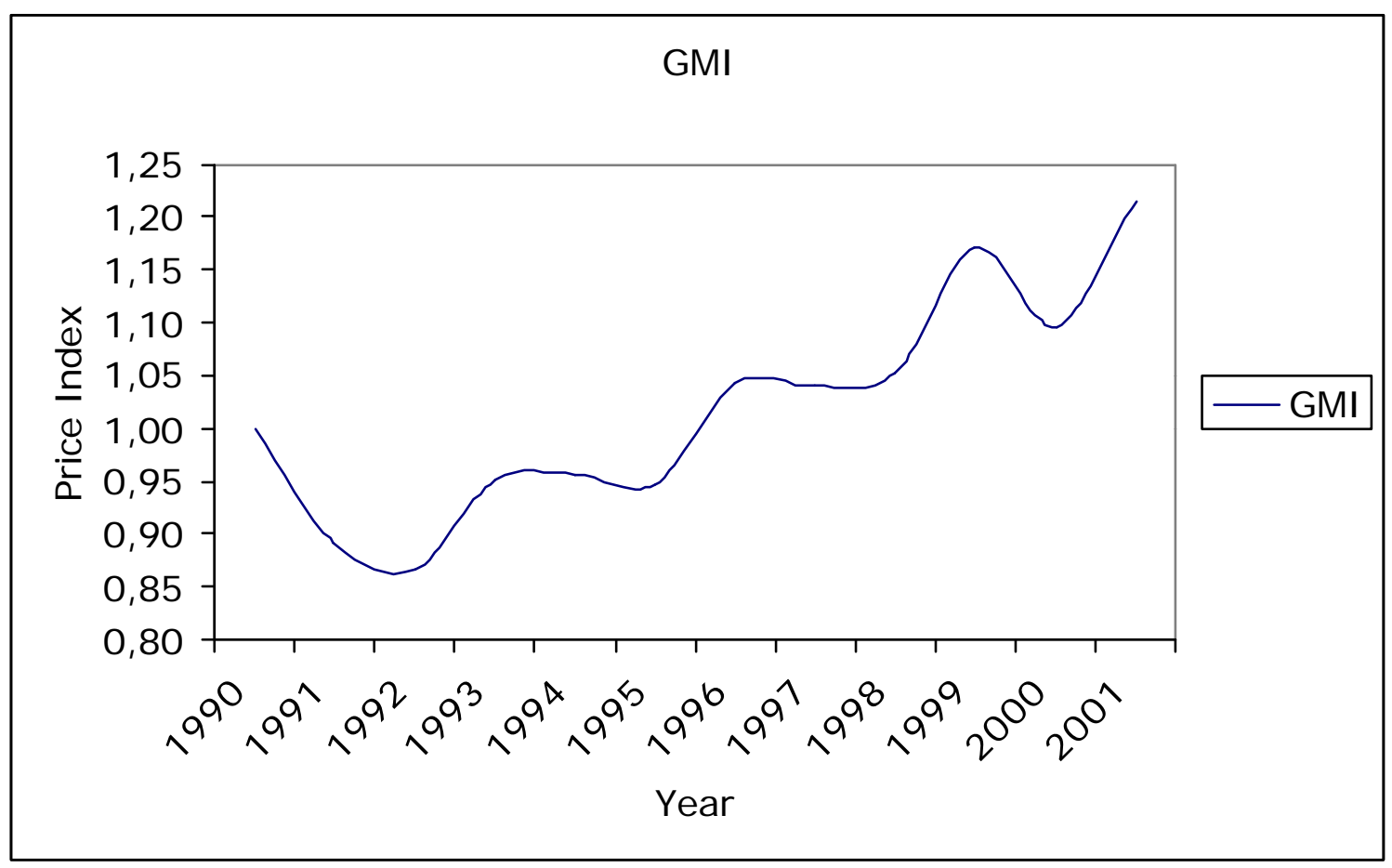


Figure 9 - Modern and Contemporary Market I ndex

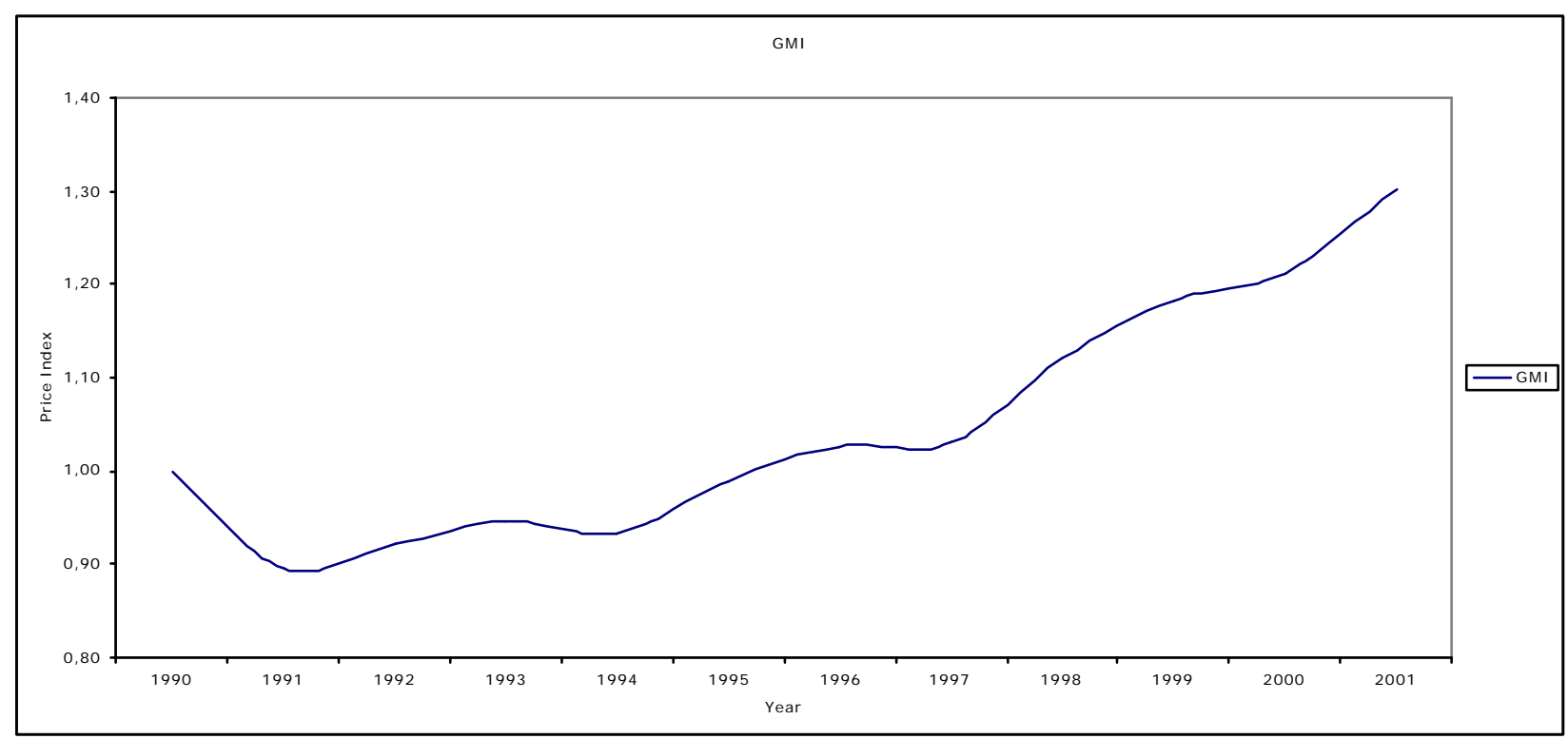

